\title{
Nerve Transfers for an Upper Brachial Plexus Injury: A Case Report
}

\section{Ferry Senjaya}

Department of Neurosurgery, Siloam Hospitals TB Simatupang - University of Pelita Harapan, Tangerang, Jakarta, Indonesia

\section{ABSTRACT}

Objective: To demonstrate multiple nerve transfers as primary surgical management for an upper plexus injury.

Methods: A 6-year-old boy who suffered a preganglionic upper brachial plexus injury following a motor vehicle accident, exhibited complete biceps, deltoids, suprapinatus, and infraspinatus palsies. Multiple nerve transfers, which consist of spinal accessory nerves to suprascapular nerve transfer, median and ulnar motor fascicles to biceps and brachialis motor branches transfers, and long head of triceps motor branch to axillary nerve transfer were performed 6 months after injury.

Results: 13 months post multiple nerve transfer, the patient has regained M4+/5 elbow flexion, M4/5 external rotation, and M4/5 shoulder abduction.

Conclusion: Nerve transfer is a viable option for upper plexus palsy management. With a sound surgical technique and good case selection, the results can be very rewarding. This case showed quite robust re-innervation with significant functional recovery at a one-year follow-up following multiple nerve transfers.

Keywords: Brachial Plexus Injury, Upper Plexus Injury, Nerve Root Avulsion, Nerve Transfers, Functional Recovery

\section{INTRODUCTION}

A brachial plexus injury is the most severe form of neurological injury affecting the upper limb. It may result from a number of mechanisms, with traumatic stretch injury being one of the most common and important. Without proper treatment, brachial plexus injuries

Received in March 2014 and accepted for publication in April 2014.

Correspondence detail: Ferry Senjaya. jl. Gunung Raya 55, Cluster Gunung Raya Kav 21A, Cirendeu, Ciputat timur, Tangsel, Banten. ferry_senjaya@yahoo.com often result in severe and permanent disability, psychological anxiety and potential economic hardship due to unemployment. In general, brachial plexus injuries can be classified as upper plexus injuries, lower plexus injuries, and pan plexus injuries. In an upper plexus injury, the involved nerve roots are C5-C6, with or without $\mathrm{C} 7$ involvement. Patients with complete lesions of the C5-C6 nerve roots exhibit an inability to abduct and externally rotate the shoulder, inability to flex the elbow, and supinate their forearm. Sensory loss is in the $\mathrm{C} 5$ and $\mathrm{C} 6$ dermatomes.

Treatment of brachial plexus injuries is either conservative or operative. Operative 
options include nerve reconstruction using nerve grafts, nerve transfer and free muscle transfer with nerve transplantation. Nerve transfer is an emerging management option for brachial plexus reconstruction following a severe injury. It offers comparable, and at times, better functional recovery than anatomical reconstruction using nerve grafts. In a certain situation, such as nerve root avulsion (preganglionic injury), it is the only option available for nerve repair.

Nerve transfer involves the repair of a distal denervated nerve element by using a proximal foreign nerve as the donor of neurons and their axons to re-innervate the distal targets. ${ }^{1,2,3}$ The concept is to sacrifice the function of a lesser-valued donor nerve to revive function in the recipient nerve and muscle, which is considered functionally more critical than the donor nerve. ${ }^{3}$

Nerve transfer is not a newly devised procedure. In 1913, Tuttle published the first report of nerve transfers in an attempt to restore function after a brachial plexus injury by using spinal accessory nerve as well as elements of cervical plexus as donor nerves. ${ }^{1,3}$ However, the excellent results of the nerve grafting techniques introduced by Millesi and Narakas in the 1960s and 1970s relatively obscured these nerve transfer techniques and nerve grafts became the standard for reconstructing nerve lesions. ${ }^{2,4}$ Nerve transfers were considered as a last resort salvage procedure when grafting was not an option. ${ }^{2}$ However, nerve graft techniques for proximal nerve injury such as a brachial plexus injury reached a plateau in its results due to the fact of finite length of time for re-innervation of the affected muscles and long-term denervated distal nerve. ${ }^{4}$ It was not until two decades ago that nerve transfer procedures were "revived" when Christophe Oberlin described the possibility of recovering the bicep muscles in an upper brachial plexus injury by transferring a motor fascicle from an adjacent ulnar nerve to the biceps motor branch distally. ${ }^{2,5}$ The idea of distal nerve transfer is appealing because transferring an expendable nerve closer to the target muscle would theoretically expedite re-innervation and obviates the need for interpositional grafts (in most cases), both of which potentially improve the outcome.

There are several fundamental principles to maximize the outcome in motor nerve transfers: A) The recipient nerve should be repaired as close as possible to the target muscle to ensure the shortest amount of time for re-innervation in an attempt to minimize distal nerve denervation and motor endplate changes; B) The donor nerve should be from a muscle whose function is expendable or has redundant innervation; C) Nerve repair should be performed directly, without intervening graft; D) The use of a donor nerve with pure motor fibres will maximize muscle fibre reinnervation; E) The donor nerve should have a large number of motor axons and be a reasonable size match to the recipient nerve; F) To facilitate motor re-education, a donor nerve that has a function synergistic to the muscle to be reconstructed should be used, as cortical re-adaptation is the physiological basis of functional recovery; and G) Motor re-education will improve functional recovery postoperatively. ${ }^{3,4}$

Nerve transfer can be accomplished without an appreciable loss of function from the donor muscle group. This is possible because nerve transfer can be performed with only a portion of the donor nerve, thus not entirely denervating the muscle associated with the donor nerve. ${ }^{6,7}$ Although this results in a reduced number of axons to the original muscle, the residual motor axons sprout within the muscle and innervate orphaned muscle fibres to enlarge the motor unit. Each motor axon can increase innervation up to five times the number of muscle fibres that it originally served, a phenomenon which is termed "adoption" ${ }_{8,9}^{8}$ In time, the donor muscle may regain its original strength. 


\section{METHODS}

The patient was a 6-year-old, right hand dominant boy. He was presented to our clinic with a 5 month history of right arm paralysis following a motorcycle accident. Immediately after the injury, he could not lift his right arm or flex his elbow (Figure 1). He also complained of numbness in his right shoulder, arm, and thumb. He did not complain of any significant pain involving his arm or shoulder. After 5 months of waiting without any evidence of improvement, he was referred to our neuroscience clinic. Upon examination, there was marked atrophy of the right deltoid, biceps, supraspinatus, and infraspinatus. Pseudosubluxation of the humeral head from the glenohumeral joint was also present. Cranial nerve examination was normal, without evidence of Horner Syndrome. The right rhomboid and serratus anterior were paralyzed. Motor strength was also absent in the following muscles: deltoid, supraspinatus, infraspinatus, biceps, brachioradialis, and supinator. Trapezius, triceps, flexor carpi ulnaris, flexor carpi radialis, intrinsic and extrinsic hand muscles were all of normal strength. There was a marked decreased sensation in light touch and pinprick in the right C5-6 dermatomal distributions. The reflex examination revealed an isolated absence of the right biceps and brachioradialis reflexes. The remainder of the neurological examination was normal. A chest X-ray (not shown) showed an elevated right hemidiaphragm, and loss of excursion; evidence of phrenic nerve palsy. This finding, along with rhomboid and serratus anterior palsy showed that he suffered a very proximal injury, i.e. nerve root avulsion. He was diagnosed with a preganglionic upper plexus injury (C5-6); therefore any further waiting would be fruitless. Given the nature of the injury, anatomical brachial plexus reconstruction using a nerve graft was not indicated, because any attempted repair to distal the level of injury/avulsion would be futile.

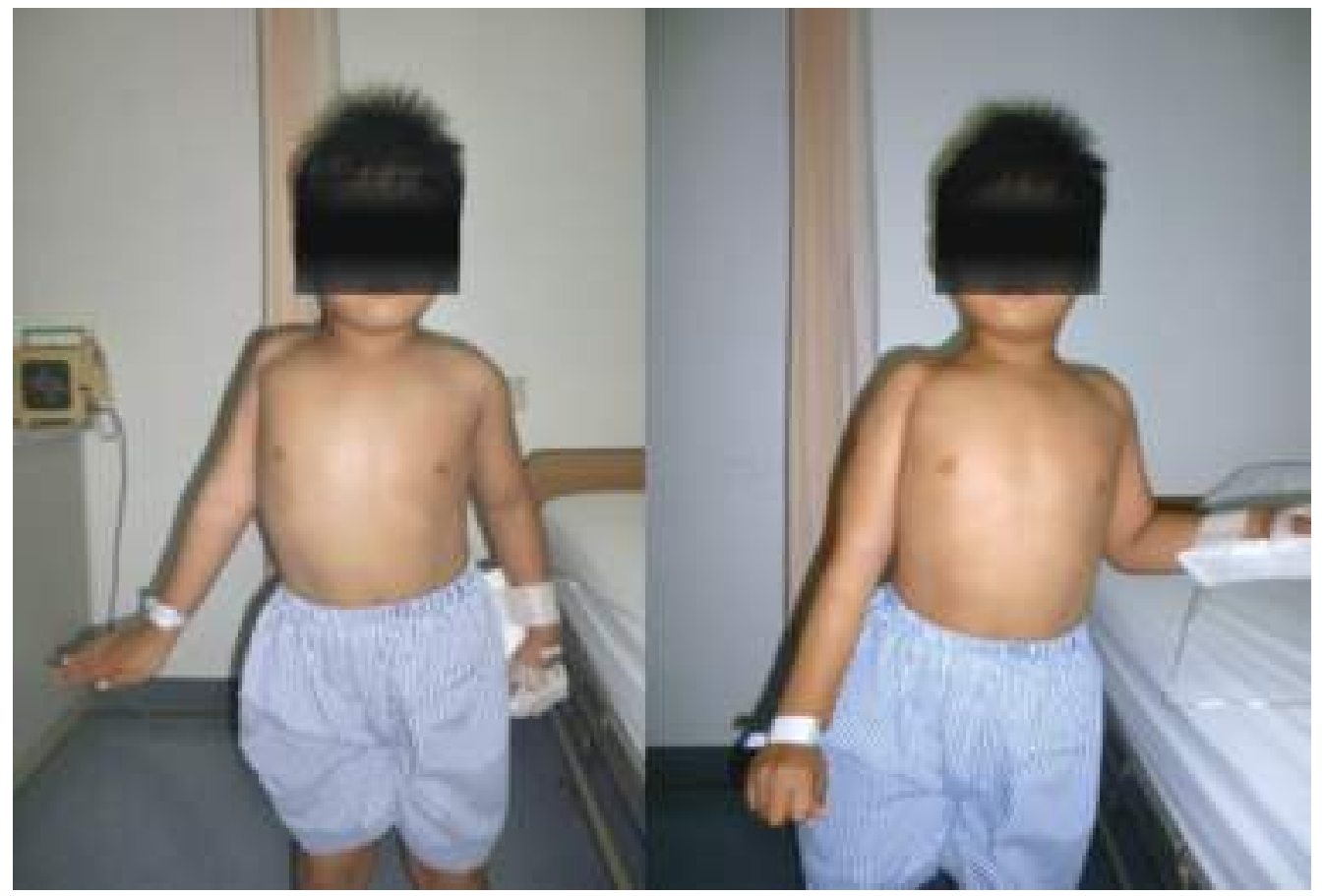

Figure 1. Before surgery, the patient was unable to abduct his right shoulder (left picture) and flex his elbow (right picture) 


\section{RESULTS}

Multiplenervetransferstargeting reconstruction of elbow flexion and shoulder abduction was contemplated. Keeping this in mind and considering the wide array of possible transfers, we decided to perform spinal accessory nerve (SAN) to suprascapular nerve (SSN) transfer to re-innervate supra and infraspinatus, double fascicular transfer (Oberlin plus procedure) using motor fascicles from ulnar and median nerve to biceps and brachialis motor branches of musculocutaneous nerve (MCN), and long head of triceps motor branch of radial nerve to axillary nerve transfers to re-innervate the deltoid. The surgery was performed 6 months after the injury, and performed as a two-staged procedure. The SAN to SSN, and double fascicular transfer to $\mathrm{MCN}$ branches were performed as the first stage (Figure 2-5). The second stage surgery is a radial to axillary nerve transfer; which was performed a month later (Figure 6). Details regarding the surgical approach and technique are beyond the scope of this article and will not be discussed here.

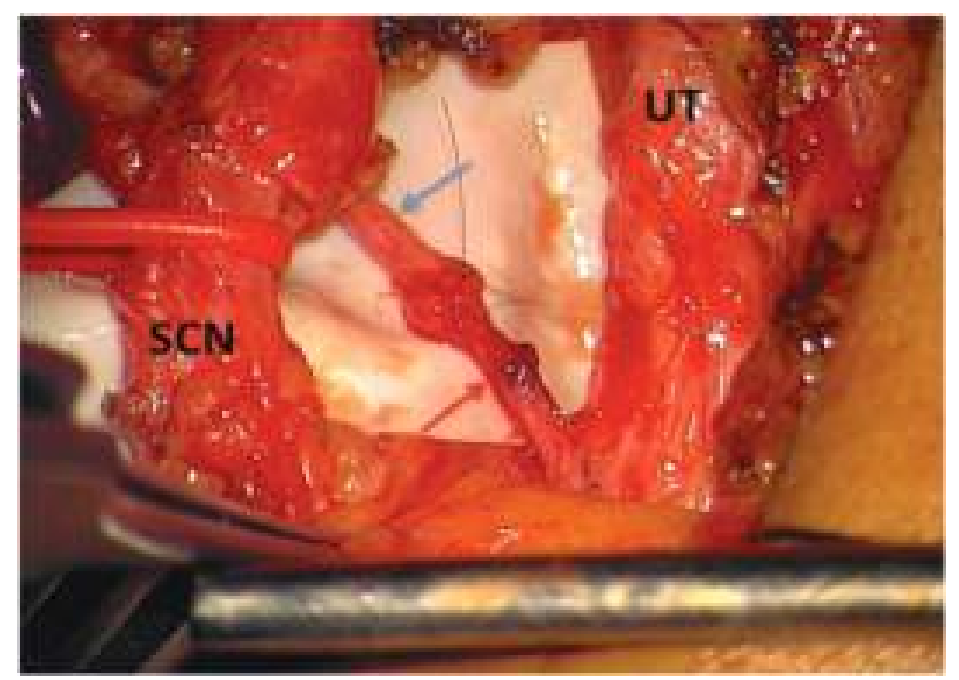

Figure 2. Right Spinal Accesory Nerve (blue arrow) to Suprascapular Nerve Transfer (red arrow). UT: Upper Trunk, SCN: Supraclavicular nerve. Top is cranial, right is medial.

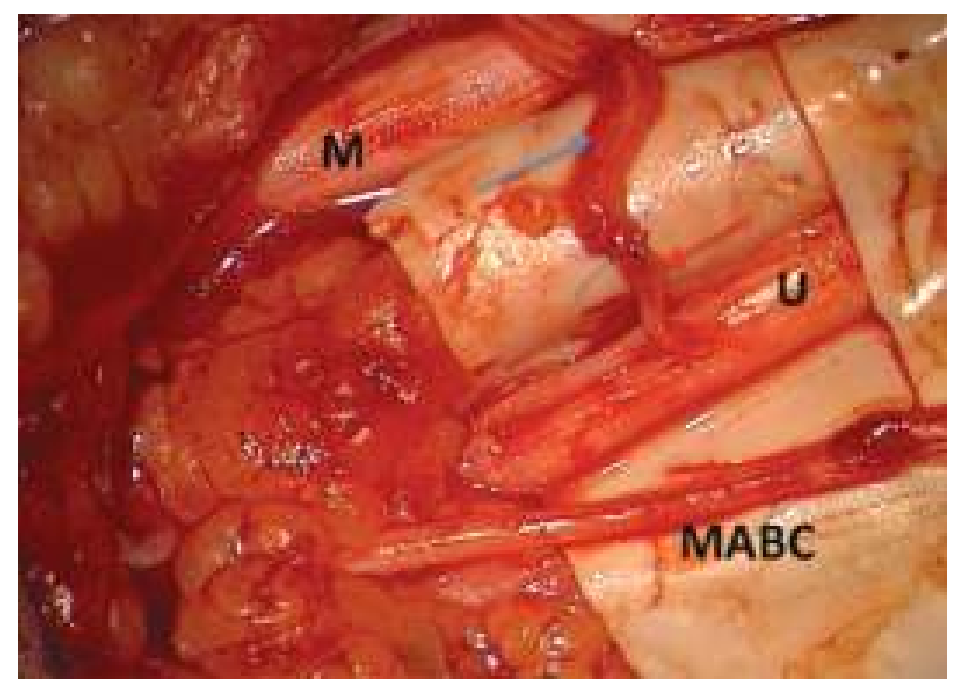

Figure 3. Right Ulnar Motor Fascicle (red arrow) to Brachialis Motor Branch of Musculocutaneous Nerve Transfer (blue arrow). M: Median nerve, U: Ulnar nerve, MABC: Medial Antebrachial Cutaneous Nerve. Top is lateral, and right is proximal. 


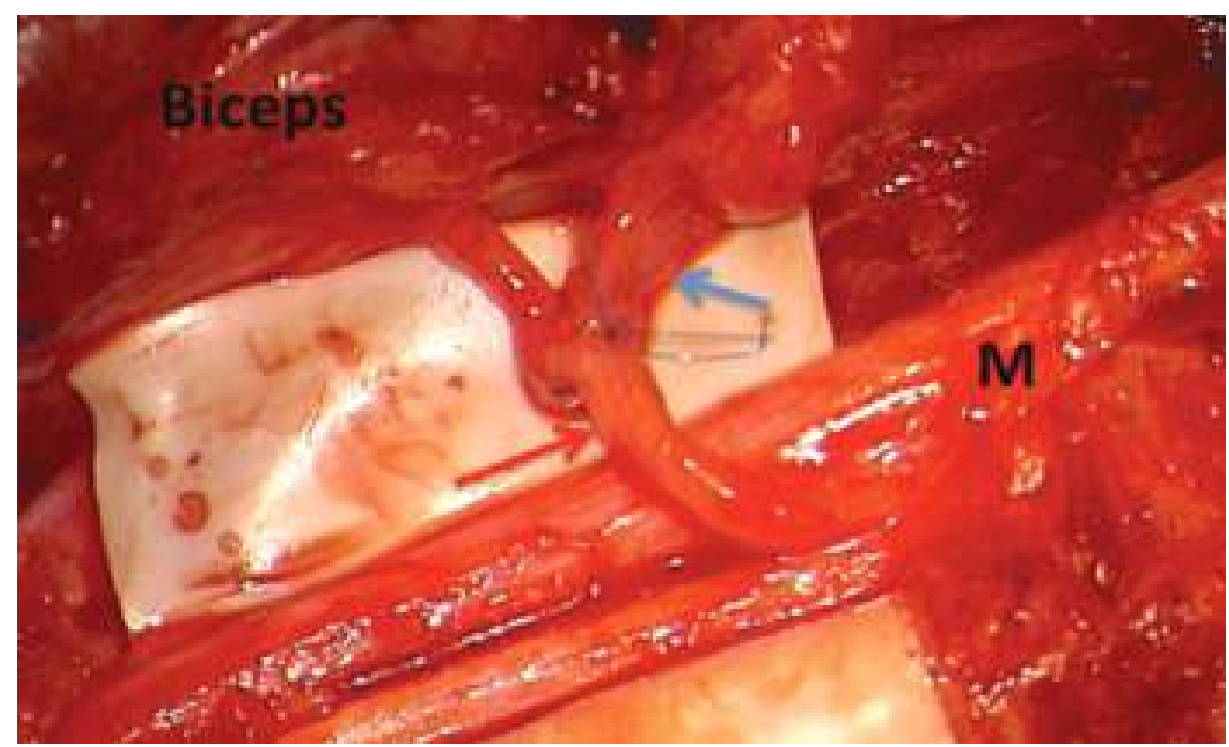

Figure 4. Right Median Motor Fascicle (red arrow) to Biceps Motor Branch(es) of Musculocutaneous Nerve (blue arrow) transfer. M: Median nerve. Top is lateral, and to the right is proximal.

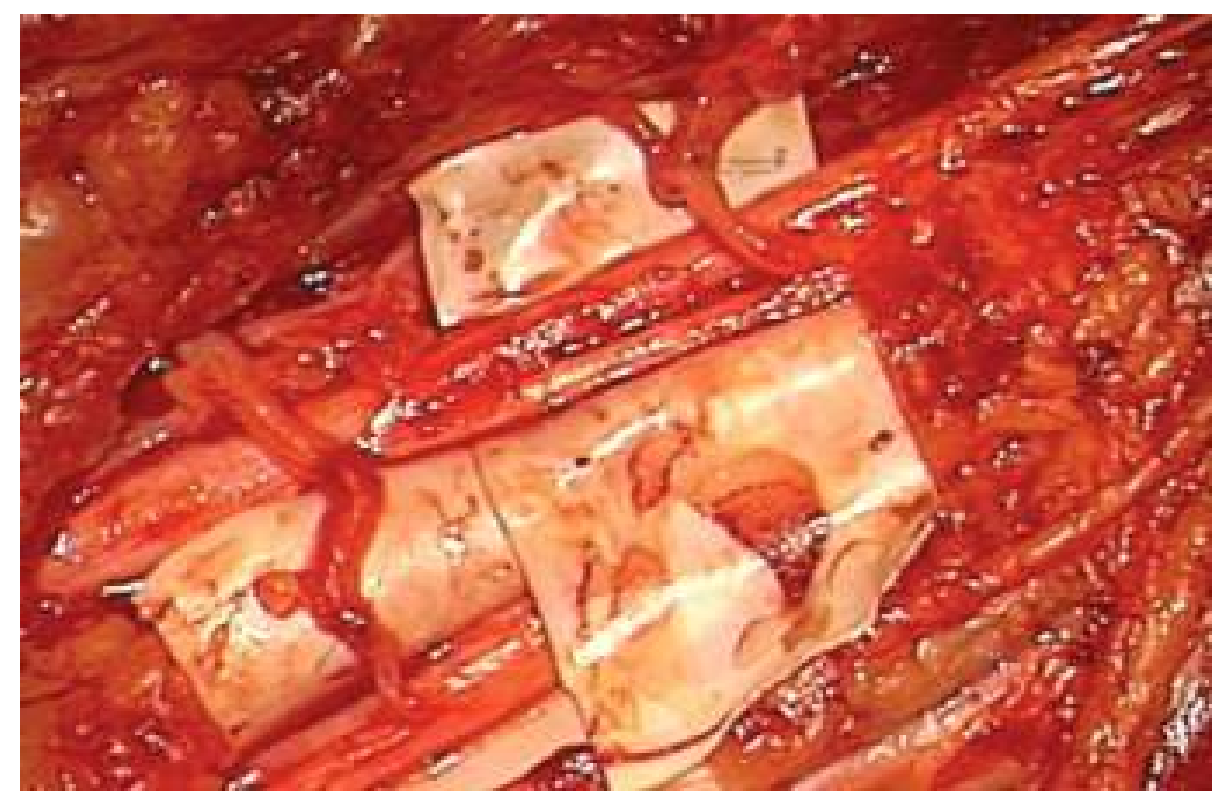

Figure 5. Complete View of Double Fascicular Transfer. Top is lateral, to the right is proximal. 


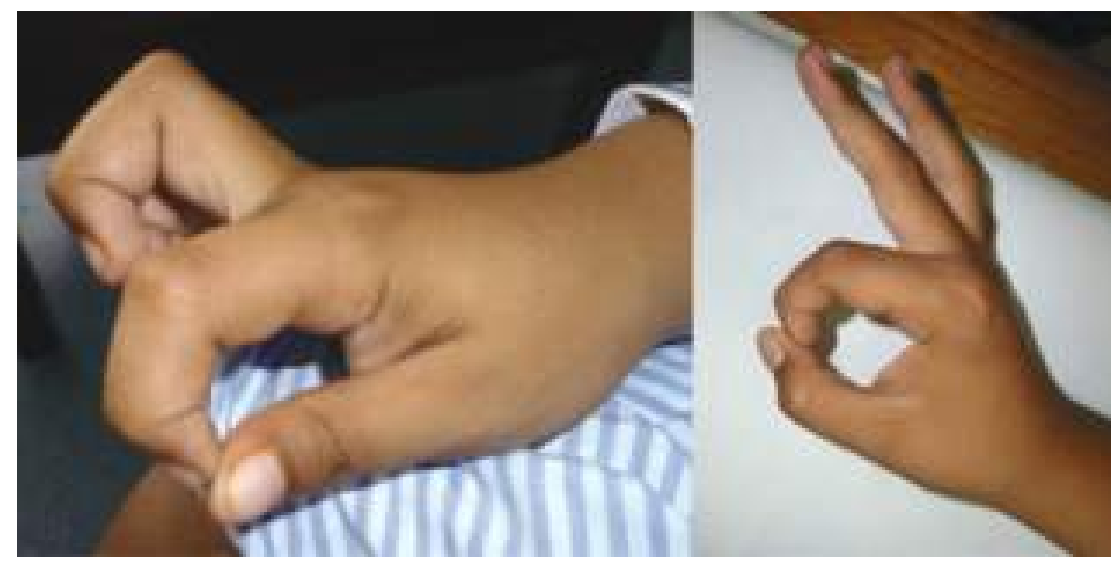

Figure 6. Post operatively, the patient exhibited weakness of right flexor pollicis longus (innervated by anterior interosseus nerve) (left picture). This returned almost completely within 2 months (right picture).

Immediately after injury, he had temporary palsy of the anterior interosseus nerve (M4-), which recovered fully within 2 months (Figure 7). The trapezius and triceps remained strong after surgery. His post surgical recovery was otherwise uneventful. Intensive physical rehabilitation was started at three weeks after surgery. Evidence of first contraction of biceps was noticed at 6-month follow up (M3). Patient first noticed that he could flex his biceps at 5 months post surgery. At 9-month follow-up, his biceps improved to M4/5, and infraspinatus started to show some function (M3). The deltoid and supraspinatus also started to function, with the patient able to abduct his arm for $30^{\circ}$. At last follow-up, 13 months away from surgery, he had achieved M4+/5 for biceps, M4/5 for infraspinatus, M4/5 for supraspinatus, M4/5 for deltoid (Figure 8). The patient could abduct his arm above shoulder level and was able to bring his hand to his mouth. The scapular winging remained, as this was not targeted at surgery. A possible option for this is pectoralis major muscle transfer, which can be done at any time. There is some residual numbness involving his C6 dermatome. Final result is expected in two years after surgery.

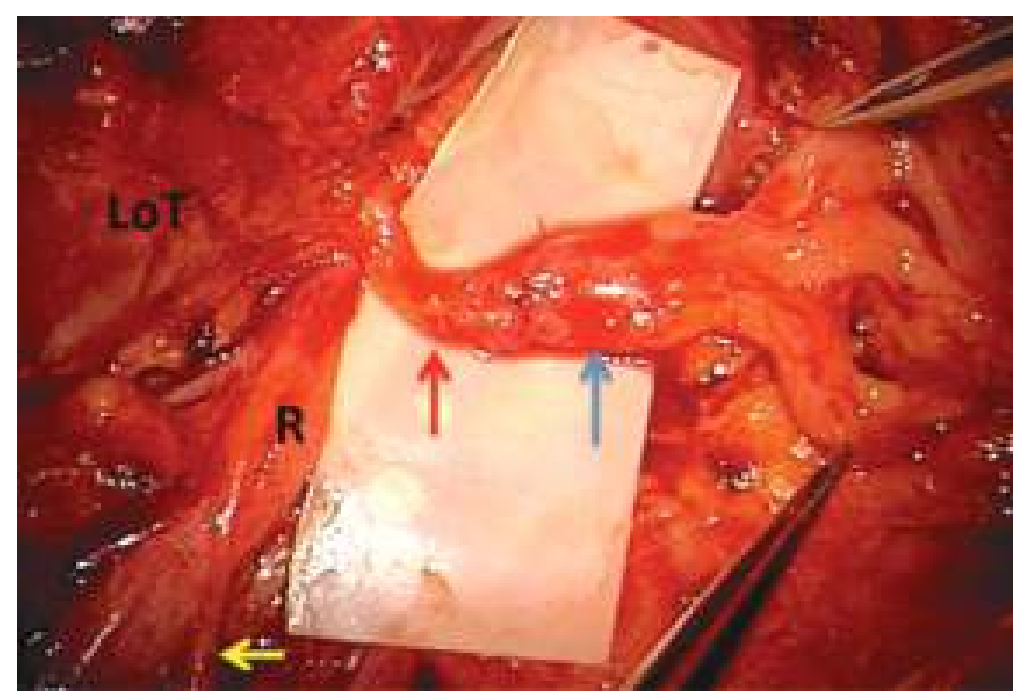

Figure 7. Right long head of triceps motor branch (red arrow) to axillary nerve (blue arrow) transfer. The proper radial nerve (yellow arrow) is seen travelling distally. LoT: Long head of Triceps, R: Radial nerve. Top is cranial, to the right is lateral. 


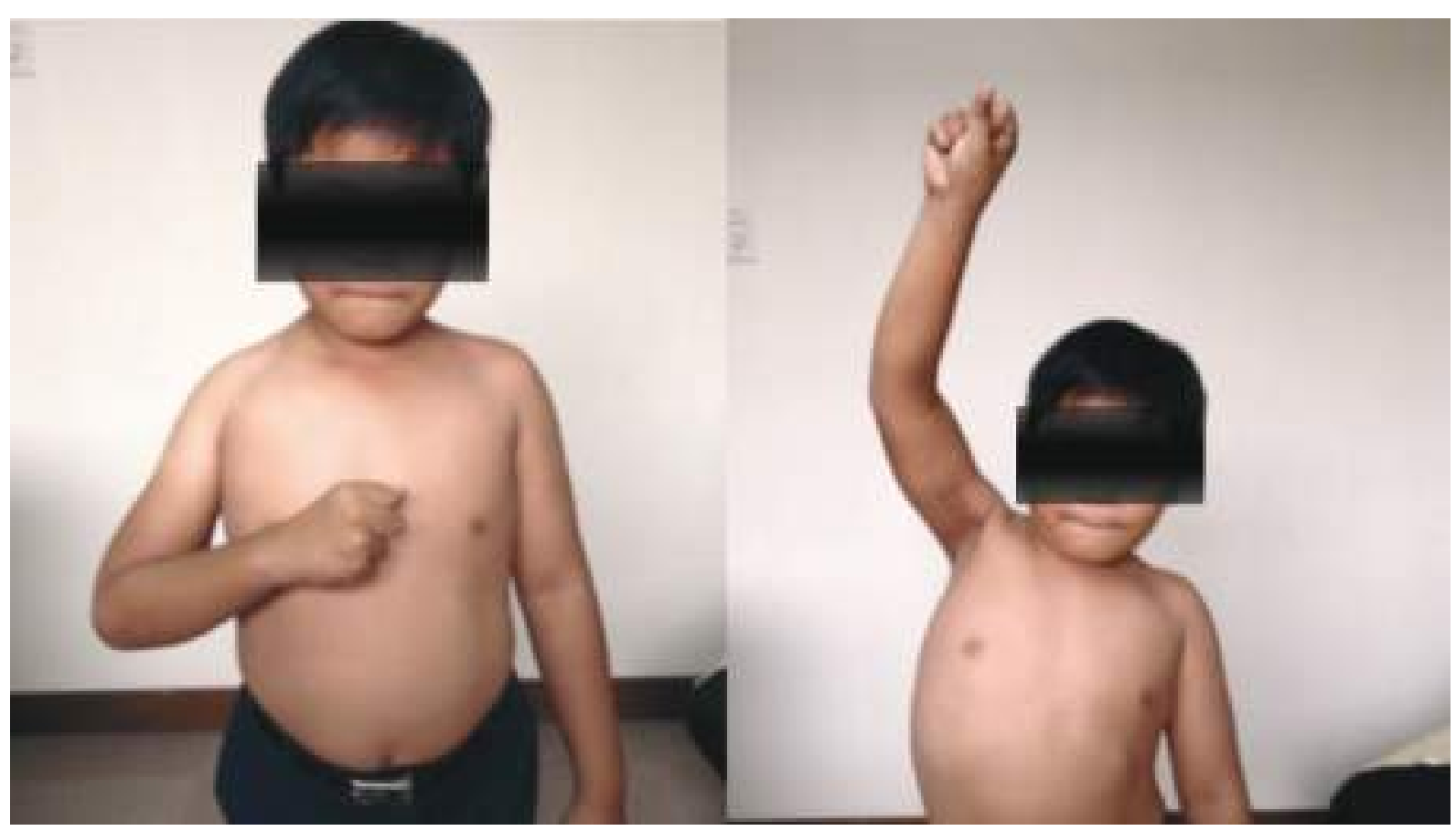

Figure 8. Outcome at 13 Months After Surgery. The patient achieved M4+ elbow flexion (left picture), and was able to elevate arm over the head (right picture).

\section{DISCUSSION}

A brachial plexus injury is a debilitating condition, which potentially leaves the victims with permanent disability if not treated optimally. In Indonesia, incidences of trauma due to motor vehicle accidents are still high. It is safe to say that the incidence of brachial plexus injuries is quite significant. Unfortunately, we don't have the data to estimate the exact incidence of brachial plexus injuries. Often, the management is suboptimal. This can be due to a number of reasons. First, the brachial plexus injury may not be obvious initially, e.g. in multiple trauma patients, or in patients with a decreased level of consciousness. Second, an ultraconservative approach by the physician taking care of the patient with a brachial plexus injury, with a prolonged period of observation, hoping that the patient will recover on their own, until it's too late for the patient to have a nerve reconstruction procedure. Third, to our knowledge, there are not many centres in Indonesia that have the facilities and the expertise for nerve repair procedure, especially for complex procedures such as in brachial plexus injuries. Unfortunately, there are many surgeons in Indonesia who still consider brachial plexus reconstruction not worth pursuing due to the complexity and the long hours taken for the procedure, and perhaps, disappointing results in some, if not many cases.

Nerve repair, especially for motor recovery, is a time-sensitive procedure. Prolonged denervation will render the muscle resistant to re-innervation. This is thought to be as a result of permanent changes of the motor-end-plate after prolonged denervation (>18-24 months). ${ }^{10-14}$ Considering the time taken for the regenerative axon to reach the muscle, as a rule of thumb, a nerve repair procedure should be performed within a year after injury, ideally before 6 months, to achieve the best result. In a postganglionic injury, an initial waiting period is applied to assess the possibility of spontaneous 
recovery. Physical therapy and rehabilitation are administered early to preserve joint mobility. If there is no evidence of clinical or electrical recovery after 6 months, then it is prudent to proceed with a nerve repair procedure. ${ }^{15-17}$ In a preganglionic injury, a waiting period is not advised, since there is no chance of spontaneous recovery. Surgery should be instituted early in order to achieve the best chance for functional recovery. ${ }^{17,18}$

With this particular patient, the presence of rhomboid, serratus anterior, and hemidiaphragm palsies suggested that the patient suffered nerve root avulsion or a preganglionic injury. This is because the branching points of the nerves dedicated to those muscles (dorsal scapular nerve to rhomboids, long thoracic nerve to serratus anterior, and phrenic nerve to diaphragm) are located very proximally on the nerve root, therefore loss of function of these nerves suggests an injury more proximal to its branching point, i.e. nerve root avulsion.

In root avulsion injuries, surgeons are devoid of the option to do an anatomical brachial plexus reconstruction using nerve grafts ${ }^{17}$ Nerve transfer is the only viable option for primary nerve repair. ${ }^{14,16,17}$ In the event of preganglionic avulsions of the C5 and C6 roots, there are several nerve transfer options that exist to restore shoulder abduction and elbow flexion. Potential donor nerves in this case include the spinal accessory nerve, the triceps motor branches of the radial nerve, medial pectoral nerve, ulnar and median nerve fascicles, intercostal nerves, and the contralateral $\mathrm{C} 7$ root.

In an upper plexus injury, the patient is unable to abduct the shoulder, supinate the arm, and flex the elbow. If $\mathrm{C} 7$ is not involved, elbow extension is normal. Hand and wrist functions are normal. The restoration of elbow flexion is deemed to be the highest priority with a brachial plexus injury, followed by shoulder stability and abduction. We attempt dual re-innervation of both the elbow (biceps and brachialis) and shoulder (supraspinatus and deltoid) muscles whenever possible. Double fascicular transfers or an Oberlin plus procedure using motor fascicle from median and ulnar nerve are gaining popularity because they provide donor axons close to the motor end plate target. ${ }^{18-20}$ In this case, we transferred motor fascicle from the median nerve to re-innervate biceps and ulnar motor fascicle to re-innervate brachialis muscle. Immediately after the surgery, the anterior interosseus nerve (a branch of median nerve) function was decreased to M4-/5, however, its function returned completely within 2 months. Anterior interosseus nerve palsy is a possible complication from taking median nerve fascicle. In most cases, it will recover within a few months, although permanent paralysis of this nerve has also been reported.$^{18}$ The patient started to notice elbow flexion 5 months after surgery, and achieved M4+/5 elbow flexion in 13 months.

To reanimate the shoulder, we chose to do dual re-innervation using spinal accessory nerve transfer to the suprascapular nerve, and long head of triceps motor branch of the radial nerve to the axillary nerve. The SAN to SSN transfer was performed on the first surgery, and triceps motor branch to the axillary nerve transfer was performed a month later. After surgery, the patient did not experience any weakness of his trapezius and triceps. At 9 months post surgery, the patient achieved M3 external rotation (infraspinatus) and $30^{\circ}$ shoulder abduction. At 13 months after surgery, the patient could bring his arm all the way up, and bring his hand to his mouth. He achieved M4 infraspinatus and supraspinatus, and M4 deltoid. His previously noted shoulder pseudosubluxation had substantially improved, showing satisfactory shoulder stability. We expect further improvement of his functions with a possible final outcome 2 years post surgery. 


\section{CONCLUSION}

Nerve transfers are being increasingly used by peripheral nerve surgeons in different situations and combinations to achieve broader and better functions. It is a viable option for upper plexus palsy management. Its use in cases of preganglionic injury allows recovery in otherwise "irreparable" lesions. Early recognition, investigation, and if necessary, surgical intervention are essential to maximize functional recovery. This case showed quite robust re-innervation with significant functional recovery of his elbow and shoulder functions at the one-year follow-up meeting following multiple nerve transfers.

\section{REFERENCES}

1. Addas BM, Midha R. Nerve transfers for severe nerve injury. Neurosurg Clin N Am. 2009; 20(1):27-38.

2. Brown JM, Vivio N, Sheean GL. The clinical practice of reconstructive neurosurgery. Clin Neurol Neurosurg. 2012;114(5):506-14.

3. Midha R. Nerve transfers for severe brachial plexus injuries: a review. Neurosurg Focus. 2004;16(5):E5.

4. Humphreys DB, Mackinnon SE. Nerve Transfers. Operative techniques in plastic and reconstructive surgery. 2002;9(3):89-99.

5. Oberlin C, Beal D, Leechavengvongs S, Salon A, Dauge MC, Sarcy JJ. Nerve transfer to biceps muscle using a part of ulnar nerve for C5-C6 avulsion of the brachial plexus: anatomical study and report of four cases. J Hand Surg (Am). 1994;19(2):232-7.

6. Brown JM. Nerve transfers in tetraplegia I: Background and technique. Surg Neurol Int. 2011;2:121.
7. Brown JM. The Reconstructive Neurosurgery of Spinal Cord Injury. In: Dimitrijevic MR, Kakulas BA, McKay WB, Vrbova G, editors. Restorative Neurology of Spinal Cord Injury. New York: Oxford University Press; 2012. p. 134-68.

8. Gordon T, Yang JF, Ayer K, Stein RB, Tyreman N. Recovery potential of muscle after partial denervation: a comparison between rats and humans. Brain Res Bull. 1993;30(3-4):477-82.

9. Brunelli G, Brunelli F. Partial selective denervation in spastic palsies (hyponeurotization). Microsurgery. 1983;4(4):221-4.

10. Aydin MA, Mackinnon SE, Gu XM, Kobayashi J, Kuzon WM, Jr. Force deficits in skeletal muscle after delayed reinnervation. Plast Reconstr Surg. 2004;113(6):1712-8.

11. Fu SY, Gordon T. Contributing factors to poor functional recovery after delayed nerve repair: prolonged axotomy. J Neurosci 15(5 Pt 2):3876-85, 1995.

12. Fu SY, Gordon T: Contributing factors to poor functional recovery after delayed nerve repair: prolonged denervation. J Neurosci. 1995; 15(5 Pt 2):3886-95.

13. Gordon T, Fu SY. Long-term response to nerve injury. Adv Neurol. 1997; 72:18599.

14. Nath RK, Shenaq SM, Lee R, Nelson M. Neurotization in Brachial Plexus Injury. In: Midha R, Zager EL, editors. Surgery of Peripheral Nerves: A Case-Based Approach. New York: Thieme Medical Publisher, Inc.; 2008. p. 46-9.

15. Addas BM, Midha R. Nerve Transfers for Shoulder Reanimation. In: Midha R, Zager EL, editors. Surgery of Peripheral Nerves: A Case-Based Approach. New York: Thieme Medical Publishers, Inc.; 2008. p. 55-9. 
16. Kam AC, Kim DH. Upper Brachial Plexus Injury (Duchene-Erb Palsy). In: Midha R, Zager EL, editors. Surgery of Peripheral Nerves: A Case-Based Approach. New York: Thieme Medical Publisher, Inc.; 2008. p. 9-13.

17. Kretschmer T, Tiel RL. Brachial Plexus Avulsion - Diagnostic Issues. In: Midha R, Zager EL, editors. Surgery of Peripheral Nerves: A Case Base Approach. New York: Thieme Medical Publisher, Inc.; 2008. p. 3-8.

18. Grondin RT, Durand S, Oberlin C. Fascicular Nerve Transfers to Restore
Elbow Flexion. In: Midha R, Zager EL, editors. Surgery of Peripheral Nerves: A Case-Based Approach. New York: Thieme Medical Publisher, Inc.; 2008. p. 60-4.

19. Tung TH, Mackinnon SE. Nerve transfers: indications, techniques, and outcomes. J Hand Surg (Am). 2010; 35(2):332-41.

20. Tung TH, Novak CB, Mackinnon SE. Nerve transfers to the biceps and brachialis branches to improve elbow flexion strength after brachial plexus injuries. J Neurosurg. 2003; 98(2):313-8. 